\title{
CARACTERIZACIÓN DEL LIBRO DE TEXTO DE CASTELLANO PARA LA EDUCACIÓN PRIMARIA COLOMBIANA: TIPOLOGÍA Y COMPONENTES
}

\author{
Isabel Borja Alarcón \\ Universidad Distrital Francisco José de Caldas, Colombia
}

\section{INTRODUCCIÓN}

En las sociedades alfabetizadas, los textos escritos cumplen diferentes funciones que facilitan la dinámica social; por medio de ellos las personas ubicadas en tiempos y espacios diferentes comparten un número importante de experiencias y es posible heredar, generacionalmente, un significativo cúmulo del conocimiento construido.

Los textos escritos que cumplen la función de servir de apoyo al proceso de enseñanza-aprendizaje revelan dos componentes, el contenido y su soporte material, en función del desarrollo de dicho proceso; a este tipo de escritos pertenecen los libros de texto.

Los libros de texto son prioritarios para el logro de los fines de un número significativo de instituciones escolares colombianas que atienden la enseñanza primaria porque, generalmente, ellos son el recurso didáctico en que más se apoya el desarrollo del trabajo de los profesores y estudiantes. En comunidades educativas deprimidas económicamente, si es preciso seleccionar un solo texto, la decisión es por el de castellano. Las casas editoriales colombianas ofrecen actualmente a las instituciones educativas un número aproximado de 25 títulos dirigidos a cada uno de los grados de primaria. Este artículo se ocupa de la caracterización de los libros de texto de castellano para la educación primaria colombiana (EPC).

\section{DESARROLLO}

El proceso de enseñanzaaprendizaje revela componentes humanos (el profesor y los estudiantes) y didácticos que, según Álvarez de Zayas [1], son los componentes de estado (el problema, el objeto, el objetivo, el contenido y el resultado) y los operacionales (el método, el medio y la forma). Con respecto al medio, los especialistas del Ministerio de Educación de Cuba (MINED) [2] señalaron que está constituido por las imágenes y las representaciones de objetos y fenómenos que se elaboran con fin didáctico y, también, por los elementos naturales que se utilizan como apoyo al proceso de enseñanza-aprendizaje. Los medios didácticos contribuyen a crear las condiciones para que los estudiantes asimilen ${ }^{1}$ los contenidos de la enseñanza en todos los niveles que dicha actividad implica. Los autores en referencia indicaron que los métodos y los medios están determinados por el objetivo y el contenido y que le corresponde al profesor seleccionar los métodos y medios más eficaces para la enseñanza de este; también, conc eptuaron que los medios se clasifican en: 1) objetos naturales e industriales (animales vivos, máquinas); 2) objetos impresos y estampados (láminas, libros); 3) medios sonoros y de proyección (películas, diapositivas); 4) materiales para la enseñanza programada y de control (máquinas para enseñar, libros de enseñanza programada).

\footnotetext{
${ }^{1}$ Belozértsev y otros [3: 142] conceptuaron que asimilar es "saber reproducir precisamente la forma dada y el modo de realizar la actividad (su componente reproductivo) utilizando para ello la tecnología de su ejecución estipulada"; con esta significación se utiliza la palabra referida en este trabajo.
} 
Los medios de enseñanza constituyen un sistema que los autores citados caracterizan por ser artificial (creado por el ser humano); inorgánico (pueden incluirse o excluirse elementos sin destruir su estructura); abierto y dinámico (experimentan constantes cambios e incorporan nuevos elementos).

De conformidad con la anterior clasificación, el libro de texto pertenece al grupo de los objetos impresos y estampados; sin embargo, ubicarlo en esta clase no da suficiente información acerca de sus características como medio didáctico que se ha desarrollado históricamente.

\subsection{Caracterización tipológica y didáctica}

Antecedentes de los libros de texto son las inscripciones elaboradas por los sumerios hacia $4.500 \mathrm{a}$. C. en tablillas de arcilla, que contenían el conocimiento elaborado dedicado al aprendizaje de un círculo social específico. Los libros de texto actuales se caracterizan, entre otros factores, por la masividad lograda gracias al desarrollo de la imprenta, la pérdida del monopolio eclesiástico sobre la enseñanza y el surgimiento de un sistema de enseñanza que optó por ellos como medio necesario. Importantes pedagogos han hecho su aporte al desarrollo del libro de texto como medio didáctico; entre ellos, Comenio, Diderot, Diesterweg y Ushinski. Con respecto a los tres primeros, Konstantinov y otros [4] señalaron que: 1) Juan Amos Comenio (1592-1670) conceptuó que los libros de texto de lengua debían ocuparse del conocimiento de la lengua propia de las comunidades, propuso así modificar la concepción imperante en aquella época con respecto a la prioridad que se concedía al aprendizaje de textos en latín; este autor resaltó, igualmente, que el libro de texto debía servir para posibilitar el acceso al conocimiento. Elaboró dos libros de texto: La puerta abierta a las lenguas (1631) y El mundo de la cosas sensibles en imágenes (1654) y teorizó sobre el libro de texto, indicando la necesidad de la cientificidad de su contenido, el fin didáctico que debe cumplir (hacer accesibles los contenidos a los estudiantes), su lugar en la estructura de la enseñanza (un libro para cada asignatura durante un año) y su forma (volumen pequeño); 2) Denis Diderot (1713-1784) dirigió la Enciclopedia de las ciencias, las artes y los oficios, libro que jugó un importante papel en la formación de los impulsores de la Revolución Francesa; 3) Federico Guillermo Adolfo Diesterweg (1790-1866) resaltó la importancia de los libros de texto en la enseñanza. Con respecto a K. D. Ushinski (1824-1870), Zuev [5] reportó que este escribió un libro de texto denominado La palabra materna y que señaló la importancia de un buen libro en el proceso de enseñanza-aprendizaje.

El libro de texto es un medio didáctico que revela las características generales de los libros y, de manera particular, las de aquellos que desempeñan funciones en el ámbito escolar. Todo libro comporta el contenido y su soporte material; uno de los componentes del contenido son los textos. La Estilística Funcional considera los textos teniendo en cuenta su función en el ámbito comunicativo; desde esta perspectiva, los planteamientos de Shishkova y Popok [6] aportaron en la conceptuación para la definición tipológica de los libros de texto. Estos autores consideraron que a cada una de las cinco esferas de la actividad humana le corresponde un estilo funcional que lleva el nombre de la esfera respectiva; así, señalaron la existencia de cinco estilos: el científico, cuyo propósito es dar cuenta del desarrollo de la ciencia, en cumplimiento de su función informativa; el oficial, que dirige y regula la actuación de los miembros de la comunidad, al desempeñar su función directiva; el publicitario, con función de propaganda y cuyo propósito es convencer de una idea o de un sistema de ideas; el literario, de función estética, a través del cual se busca que el interlocutor sea afectado por las imágenes artísticas mediante las cuales se recrea la realidad; el coloquial, usado para establecer la comunicación cotidiana. Con respecto al estilo funcional científico, que interesa para efectos de la caracterización de los libros de texto, los autores 
comentados indicaron que este contiene tres subestilos: 1) el propiamente científico, cuyos géneros son, entre otros, el artículo, el informe, la monografía y la tesis; 2) el de divulgación científica, a través del cual se propagan los logros científicos y que implica, además de otros géneros, el de los manuales escolares; 3 ) el subestilo científico-administrativo entre cuyos géneros están la documentación científica, las instrucciones y las cartas patentes. La autora de este texto considera que esta clasificación posibilita identificar las tipologías textuales de una manera más precisa, comparativamente con otras propuestas, ya que contempla con claridad la gama de esferas de la actividad humana, ámbito de existencia de los textos, los cuales, en tanto elementos dinámicos, pueden operar en distintas esferas. De acuerdo con los planteamientos de Shishkova y Popok, en la referencia, se puede inferir que los libros de texto son un subgénero de los manuales escolares.

Desde el punto de vista didáctico, el libro de texto fue delimitado por Klingberg [7] como el que: 1) concreta las orientaciones del plan de enseñanza; 2) da al maestro sugerencias adicionales esenciales para la planificación y conducción de la clase; 3) ayuda al enriquecimiento del instrumental metódico; 4) transmite al estudiante conocimientos fundamentales, educación e instrucción filosóficas; 5) presenta resúmenes, preguntas, estímulos para el trabajo independiente, impulsos al pensamiento y problemas para resolver. En este mismo sentido escribieron los especialistas del MINED [2].

Zuev [5: 12] definió el libro de texto escolar contemporáneo como:

"Un libro docente de masas, donde se expone el contenido de las asignaturas que forman la enseñanza y se definen los tipos de actividades que el programa escolar destina a ser asimilados obligatoriamente por los alumnos, teniendo en cuenta las particularidades de sus edades y otros."

A la diferencia entre el texto científico y el texto didáctico se refiere K. D. Ushinsky, citado por Zuev [3:10], al afirmar que los contenidos de las disciplinas:

"Se reflejan de forma muy diferente en la conciencia del maestro que en la del estudiante, y he aquí por qué la nueva pedagogía considera necesario diferenciar la exposición pedagógica de la ciencia de su exposición sistemática".

Esta concepción de K. D. Ushinsky implica que el libro de texto manifiesta en sus componentes dos aspectos: el disciplinar-didáctico y el de la redacción. El primero involucra el contenido de la disciplina específica que debe asimilar el estudiante y las determinaciones didácticas con respecto a cómo presentar la materia de estudio; el segundo viabiliza que las determinaciones disciplinares y didácticas se reflejen en el libro. Con base en la formulación arriba citada, Zuev [5] resaltó como elemento característico del libro de texto el hecho de que revela el principio de accesibilidad del conocimiento en el proceso de enseñanzaaprendizaje.

El autor en referencia señaló que al libro de texto le corresponden las siguientes funciones didácticas:

- Informativa. Presentación de la totalidad de la información indicada por el programa de la respectiva asignatura.

- Transformadora. En dos sentidos: 1) reelaboración didáctica de los contenidos; 2) conversión de la actividad puramente cognoscitiva de los estudiantes en actividad transformadora. 
- Sistematizadora. Exposición del material docente en una secuencia rigurosa sistematizada, para que el estudiante domine los procedimientos de la sistematización científica.

- De consolidación y de control. Contribución para que los estudiantes se orienten en el conocimiento adquirido y se apoyen en él para realizar la actividad práctica.

- De autopreparación. Formación en los estudiantes del deseo de aprender y de la capacidad de aprender por sí mismos.

- Integradora. Ayuda a los estudiantes para asimilar y seleccionar los conocimientos como un todo único.

- Coordinadora. Aseguramiento del empleo más efectivo y funcional de todos los medios de enseñanza y del uso de medios extradocentes de información masiva.

- Desarrolladora y educadora. Contribución a la formación activa de los rasgos esenciales de la personalidad armónica y desarrollada.

\subsection{Componentes de los libros de texto}

Zuev [5: 106] presentó su modelo general de los libros de texto por medio de un esquema que se reproduce en la figura 1 , anexo 1 . Como puede observarse en dicha figura, el libro de texto escolar implica dos componentes: los textos y los componentes extratextuales. Los textos comportan los conocimientos y actividades que deben ser asimilados por los estudiantes; los componentes extratextuales tienen por función organizar la asimilación del contenido de enseñanza y facilitar su comprensión y uso práctico. Tanto los textos como los componentes extratextuales ocupan un lugar próximo a la cúspide. Zuev [5] concibió el subsistema estructural denominado texto como compuesto por texto básico, texto complementario y texto aclaratorio, tal como se especifica a continuación:

- El texto básico comprende los textos teórico-cognoscitivos y los textos prácticoinstrumentales; estos se caracterizan de la siguiente manera: Los teórico-cognoscitivos tienen por función dominante la presentación de la información. Sus contenidos son: 1) los términos principales y el lenguaje de una esfera concreta del conocimiento científico que representa una asignatura docente dada; 2) los conceptos claves y sus definiciones; 3) los hechos principales; 4) las características de las leyes fundamentales, las regularidades y sus consecuencias; 5) el reflejo de las teorías principales; 6) las características del desarrollo de las ideas rectoras y de las direcciones perspectivas en una determinada rama del saber; 7) los materiales básicos para formar una actitud emocional-axiológica hacia el mundo; 8) las generalizaciones y valoraciones ideológicas y acerca de la concepción del mundo; 9) las conclusiones y el resumen. Los textos práctico-instrumentales cumplen una función predominantemente transformadora (aplicación de conocimientos) y sus contenidos son: 1) las características de los métodos de actividad necesarios para asimilar el material docente y obtener independientemente los conocimientos; 2) las características de los principios y reglas de aplicación de los conocimientos; 3) las características de los métodos fundamentales del conocimiento en una rama determinada del saber, incluyendo los métodos aplicados; 4) la descripción de las tareas, ejercicios, experiencias, experimentos y situaciones necesarias para deducir las reglas y generalidades para asimilar la información teórico-cognoscitiva; 5) la elaboración del conjunto de ejercicios, 
tareas, experimentos y trabajos independientes necesarios para formar el complejo de habilidades básicas; 6) las características de las normas ideológicas, morales y estéticas, necesarias para la actividad en una esfera dada; 7) las características de las operaciones lógicas y de los procedimientos necesarios para organizar el proceso de asimilación de la información teórico-cognoscitiva; 8) los resúmenes y las secciones especiales, que sistematizan e integran el material docente; 9) los elementos especiales de un texto que sirven para la consolidación e, incluso, la repetición generalizadora del material docente.

- Los textos complementarios son los que tienen por función dominante reforzar y profundizar los postulados del texto básico; sus elementos son: 1) documentos; 2) materiales antológicos; 3) fragmentos de literatura científico-popular y de memorias; 4) descripciones literarias y narraciones; 5) notas o llamadas; 6) información bibliográfica y científica; 7) resúmenes estadísticos, incluyendo tablas; 8) todo género de listas, relaciones, principales rasgos detallados de fenómenos y conceptos que puntualizan el cuadro general de acontecimientos; 9) materiales informativos de carácter complementario (que rebasan los marcos del programa de estudios).

- El texto aclaratorio cuya función dominante es servir a la comprensión ${ }^{2}$ y asimilación completa del material docente permitiendo la organización y realización de la actividad cognoscitiva independiente de los estudiantes. Tiene como elementos: 1) introducción al libro de texto o a sus diferentes partes y capítulos; 2) observaciones, notas y aclaraciones; 3) glosarios; 4) alfabetos; 5) índices; 6) pies de mapas, esquemas, planos, diagramas, gráficos y otros tipos de ilustraciones gráficas; 7) tablas de fórmulas, sistemas de unidades, coeficientes, elementos y resúmenes de normas; 8) índice (relación) de los signos convencionales adoptados en una esfera dada del conocimiento; 9) índice de las abreviaturas usadas en el libro.

Con respecto a los componentes extratextuales del libro de texto -el aparato de organización de la asimilación (AOA), el material ilustrativo (MI) y el aparato de orientación (AO)-, Zuev [5] puntualizó que la organización de la asimilación de los conocimientos por parte de los alumnos se inicia por la acción sobre su esfera emocional motivadora; en consecuencia, el autor debe tener en cuenta las necesidades de los estudiantes según su edad, la información y la actividad que para ellos sean importantes, la necesidad de autoafirmación y las tareas de la educación, entre otros aspectos. Los textos de los libros de texto deben ser accesibles, convincentes y significativos, porque deben servir para estimular y enriquecer la actividad de enseñanza para el mejor desarrollo de la actividad de aprendizaje. Este autor en referencia señaló que los componentes del AOA son: as preguntas y tareas, las respuestas a ellas y las tablas generalizadoras y sistematizadoras; también, conceptuó que el Ml tiene por función reforzar la acción cognoscitiva, ideológica, estética y funcional del material docente sobre el estudiante, para lograr su asimilación; puntualizó que sus elementos son, entre otros: las ilustraciones (artístico-figurativas, documentales, técnicas, foto-ilustrativas), los dibujos, los esquemas, los planos, los diagramas, los gráficos y los mapas. El mismo autor explicó que el AO hace factible la orientación adecuada a un propósito del estudiante, en el contenido y la estructura del libro, sentando las bases necesarias para el trabajo autónomo con él; sus elementos son: el prefacio, el

\footnotetext{
${ }^{2}$ Para Lerner y Skatkin [8] la comprensión constituye la fijación en la conciencia de los vínculos entre los objetos del mundo circundante. Esta es la acepción del término en esta tesis.
} 
encabezamiento, la rúbrica, los señalamientos con caracteres gruesos o en colores, los símbolos-señales, los índices temáticos y onomásticos, la bibliografía y los títulos.

Aunque otros autores se han ocupado de la reflexión acerca de las ilustraciones de los libros de texto -'Material llustrativo' para Zuev [5]-, su formulación no supera la de este autor, ya aludida; el acierto de ella radica en que tiene como elemento orientador la función esencial del libro de texto, a la cual se subordinan todos sus componentes.

Las caracterizaciones acerca del contenido de los libros en referencia expresadas por distintos estudiosos, entre ellos, Nolán y Goets [9], Hernández Ruiz [10], II Reunión internacional de expertos en materiales educativos y bibliotecas en español [11], Tejada [12], Tejada y daen [13], Peña [14] y [15] y Vanegas Fonseca [16], permiten afirmar que son afines a las formulaciones de Zuev [5] pero que las de este tienen carácter de mayor completitud y profundidad.

Considerando que en el Modelo del libro de texto escolar de Zuev la referencia es al contenido, pero que los libros, además del contenido, revelan el soporte material de este como otro componente ${ }^{3}$ y teniendo en cuenta que el libro de texto manifiesta los aspectos disciplinar-didáctico y de la redacción, la autora de este artículo, al tiempo que reconoce la importancia del modelo en comento, propone modificarlo, para que se evidencie, también, este otro componente; ello obliga a visualizar el modelo de tal forma que textos y componentes extratextuales constituyan el contenido, que se encontrará ubicado, con respecto a la cúspide, en el mismo nivel jerárquico que su soporte material, y que se tengan en cuenta los aspectos disciplinardidáctico y de la redacción que están involucrados en todos los componentes, tal como puede observarse en la representación del que hemos denominado 'Modelo de libros de texto de Zuev modificado' (figura 2, en el anexo 2). A continuación, la reflexión se centra en los elementos del soporte material del contenido.

El soporte material del contenido está constituido por el material de elaboración y el formato ${ }^{4}$. Dependiendo del material en que están elaborados, los libros son electrónicos o impresos en material plástico o en papel. Los cambios tecnológicos que llevan a la construcción electrónica implican modificaciones en el soporte material del contenido y en el contenido. La autora de este artículo identifica los siguientes elementos como componentes del material de elaboración de los libros que se hacen en papel: 1) la tinta; 2) las hojas; 3) las tapas o cubierta; 4) la encuadernación. Richaudeau [20] señaló la importancia del uso de las tintas a color porque despiertan el interés de los estudiantes; también llamó la atención con respecto a que el uso de ellas aumenta el costo del libro y estableció una equivalencia de incremento del costo de un libro en la misma proporción en que se utilizan más colores distintos. En el uso del color en el libro de texto, se deberá evitar la monotonía y procurar que el libro sea motivador; por ello, por ejemplo, si la decisión es por una sola tinta, se recurrirá al empleo creativo de la trama. Las determinaciones con respecto al papel para las hojas y para las tapas o cubiertas deben tomarse considerando varios criterios; De Buen Unna [21] señaló que los editores, al seleccionar el papel, además de ajustarse al presupuesto, tienen en cuenta el peso, la opacidad (evitando los materiales traslúcidos) ${ }^{5}$ y la

\footnotetext{
${ }^{3}$ Este fue denominado con términos distintos, entre otros, por Prendes Espinosa [17] y Charria V. y otros [18]

4 El formato fue definido por Moliner [19: 1328] como: "Tamaño y forma de un libro o cuaderno; el primero especificado en general por el número de hojas que se hacen con cada pliego, y ahora, con más frecuencia, por el número de centímetros de altura o de altura y anchura."

${ }^{5}$ Generalmente, los editores prefieren sacrificar el peso en favor de la opacidad; muchos de ellos buscan papeles de bajo peso y de buena opacidad.
} 
textura; buscan que el papel esté bien colado ${ }^{6}$, para que no se hidrate en exceso; también, deciden en cuanto a su resistencia y color. Lo más común es que los libros de texto tengan sus hojas en papel de 70 o 75 gramos y su cubierta de 250 gramos, usualmente, plastificada. El otro componente del material de elaboración del libro de texto es la encuadernación, que es la manera como se pegan las hojas que lo constituyen y se ponen sus tapas o cubiertas. El tipo de encuadernación más utilizado para el libro de texto es la 'encuadernación a la rústica' o 'en rústica'7

Con respecto al formato, Peña Borrero y Mejía Botero [23] señalaron que este es la base de todo el diseño gráfico del libro y que la diagramación de las páginas, el largo de línea, la interlínea y el cuerpo de la letra se determinan en relación con él. Los autores en referencia conceptuaron que en la definición del formato influyen criterios prácticos (su uso implica, casi siempre, que se abran sobre los pupitres y que se carguen para la casa y para la escuela; en ocasiones, se ubican en los estantes de bibliotecas que tienen dimensiones estándares), criterios pedagógicos (su función, la forma de interacción con él, las características psicológicas de los estudiantes que, según el grado de escolaridad, implican el dominio de un área visual determinada) y criterios industriales (racionalización de costos). Los mismos autores indicaron que los formatos más utilizados en los libros de texto, por su tamaño, son $14 \times 21$ y 21 X 28 centímetros y, por su forma, el prolongado u oblongo (donde la altura es mayor que la anchura). Estas reflexiones de Peña Borrero y Mejía Botero [23] son importantes porque nos permiten clarificar aspectos del formato del libro de texto y visualizar las características del libro como objeto de estudio complejo.

\subsection{El libro de texto de castellano para la educación primaria colombiana}

Con base en la conceptuación de Zuev [5] con respecto al contenido del libro de texto y en las formulaciones anteriores atinentes a su soporte material, la autora de este artículo conceptúa que el libro de texto de castellano para un grado de la EPC es aquel en que se encuentran presentados didácticamente los contenidos que el programa de estudios de dicha área determina que deben ser asimilados por los estudiantes de ese grado; la presentación didáctica se manifiesta tanto en el contenido como en su soporte material. Los contenidos están expresados mediante: 1) la Ley general de educación; 2) los Indicadores de logros; 3) los Estándares de calidad; 4) los Lineamientos curriculares; documentos divulgados por el Ministerio de Educación Nacional [24], [25], [26] y [27], respectivamente. El MEN [28] propuso que los libros de texto de la EPC reflejen en su contenido el plan de estudios con carácter de serie; por ejemplo, el libro 1 se entiende con continuidad en el 2 y este como antecedente del 1; así, se busca propiciar una articulación que favorezca el paso entre grados de la escolaridad, atendiendo el carácter sistémico que rige la actividad de formación escolar.

A partir de la aproximación teórica y práctica a los libros de texto y teniendo en cuenta las directrices estatales acerca de los programas de estudio para la EPC y para la selección de libros de textos, la autora de este artículo conceptúa que los libros de texto de castellano para la EPC de conformidad con sus características forman dos grupos: 1) el constituido por los libros dirigidos a los grados primero, segundo y tercero; 2) el conformado por los libros para los grados cuarto y quinto. Al interior de cada uno de estos grupos, hay diferencias que tienen que ver con los temas y con la forma de su tratamiento, en consonancia con el desarrollo que se busca que alcancen los niños de cada grado de la EPC; también hay elementos en

\footnotetext{
${ }_{7}^{6}$ Un papel bien colado es aquel conformado por fibras que se han compactado o entrelaz ado muy bien.

7 Esta fue definida por Martínez Sousa [22: 94] como: "Tipo de encuadernación ligera en la que el libro, luego de cosido y prensado, se recubre con una cubierta de papel fuerte o cartulina".
} 
común entre ambos grupos. Las similitudes y diferencias con respecto a los contenidos pueden apreciarse en la tabla siguiente que da cuenta de las directrices estatales con respecto a los componentes de estos libros, considerados a la luz del Modelo de Zuev modificado.

Componentes de los libros de texto de castellano para la EPC.

Directrices estatales

\begin{tabular}{|c|}
\hline Grados $1^{\circ}, 2^{\circ}$ y $3^{\circ}$ \\
\hline \\
\hline Texto teóric \\
\hline $\begin{array}{l}\text { Producción textual } \\
\text { 1) Textos orales. Descripción; el lenguaje: medio de } \\
\text { representación; } \quad \text { discursos; } \quad \text { entonación; } \\
\text { argumentación; competencia } \quad \text { significativa; } \\
\text { producción textual; relaciones lógicas en el discurso; } \\
\text { procesos cognitivos; intercambios simbólicos y } \\
\text { culturales; comunicación; interacción; concepción de } \\
\text { lenguaje; significación y comunicación; habilidades } \\
\text { comunicativas. }\end{array}$ \\
\hline
\end{tabular}

2) Textos escritos. Descripciones; formas de discursos; competencia extual; producción textual; relaciones lógicas en el discurso; procesos cognitivos; texto descriptivo. hipótesis de textos, interpretación y análisis; el tema general; grupos de significados; gramática: usos, giros, sentidos 0 precisiones en situaciones contextualizadas.
Interpretación textual. Comprensión de textos;
Estética del lenguaje. Comprensión de textos literarios; fines lúdicos, estéticos y prácticos de la lectura, la escritura y la imagen; cuentos, mitos, leyendas, retahílas; relación entre literatura y educación.

Otros sistemas simbólicos. Información en sistemas no verbales.

Ética de la comunicación. Elementos y roles de la comunicación; información a través de los medios; acuerdos por medio del lenguaje; compromisos éticos en la comunicación; promoción de valores.
1) Textos orales. Entonación y articulación. Procedimientos mentales (clasificación, jerarquización, seriación, comparación, definición, análisis, síntesis; parte-todo, causa-consecuencia, problema-solución); estructura, nivel lexical, sentido estético y contexto de textos; la expresión clara y segura. Competencia significativa, producción textual, relaciones lógicas en el discurso, procesos cognitivos, intercambios simbólicos y culturales, la comunicación, la interacción, concepción de lenguaje, significación y comunicación, las habilidades comunicativas

2) Textos escritos. Etrategias para su elaboración; relaciones entre pensamiento, lenguaje y realidad; planes textuales (preescritura); procedimientos mentales; estructura, léxico, sentido estético y contexto de textos; búsqueda, organización y almacenamiento de información; competencia textual, producción textual, relaciones lógicas en el discurso, procesos cognitivos, texto descriptivo.

Interpretación textual. Estrategias de búsqueda, organización y almacenamiento de información; medios de comunicación masiva y selección de la información que emiten, para ser usada en la creación de textos; diversas interpretaciones de un mismo texto o acto comunicativo, con base en hipótesis de comprensión y en competencias simbólica, ideológica, cultural o enciclopédica; estructuras semánticas y sintácticas; relaciones lógicas entre las unidades de significado de los textos y las de actos comunicativos; mecanismos textuales para la coherencia y cohesión; semejanzas y diferencias entre los tipos de textos y actos comunicativos, en significados, estructuras y contextos.

Estética del lenguaje. Caracterización del funcionamiento de algunos códigos no verbales; relación entre literatura y educación.

Otros sistemas simbólicos. Elaboración de hipótesis de lectura acerca de las relaciones entre los elementos constitutivos de un texto literario y entre éste y el contexto.

Etica de la comunicación. Conocimiento y análisis de los elementos, roles, relaciones y reglas básicas de la comunicación, para inferir; la interpretación. Selección y uso de la información que emiten los medios de comunicación; las intenciones de los participantes en actos comunicativos; las reglas básicas de los actos comunicativos; producciones culturales de la comunidad y su función social.

Textos básico práctico -instrumental: presentación de elementos que ayuden a organizar, sintetizar o relacionar la información; proposición de actividades de aprendizaje y de formas de identificar los logros del aprendizaje. 
Aclaratorio. Glosario de temas y conceptos.

Complementario. Textos literarios y otros textos que contribuyan a:

- el pleno desarrollo de la personalidad sin más limitaciones que las que le imponen los cerechos de los demás y el orden jurídico, dentro de un proceso de formación integral, física, psíquica, intelectual, moral, espiritual, social, afectiva, ética y cívica.

- la formación en el respeto a la vida y a los demás derechos humanos; a la paz; a los principios democráticos, de convivencia, pluralismo, justicia, solidaridad y equidad; al ejercicio de la tolerancia y de la libertad;

- la formación para facilitar la participación de todos en las decisiones que los afectan en la vida económica, política, adm inistrativa y cultural de la Nación;

- la formación en el respeto a la autoridad legítima y a la ley, a la cultura nacional, a la historia colombiana y a los símbolos patrios;

- la adquisición y generación de los conocimientos científicos y técnicos más avanzados, humanísticos, históricos, sociales, geográficos y estéticos, mediante la apropiación de hábitos intelectuales adecuados para el desarrollo del saber;

- el estudio y la comprensión crítica de la cultura nacional y de la diversidad étnica y cultural del país, como fundamento de la unidad nacional y de su identidad;

- el acceso al conocimiento, la ciencia, la técnica y demás bienes y valores de la cultura, el fomento de la investigación y el estímulo a la creación artística en sus diferentes manifestaciones;

- la creación y el fomento de una conciencia de la soberanía nacional y para la práctica de la solidaridad y la integración con el mundo, en especial con Latinoamérica y el Caribe;

- el desarrollo de la capacidad crítica, reflexiva y analítica que fortalezca el avance científico y tecnológico nacional, orientado con prioridad al mejoramiento cultural y de la calidad de vida de la población, a la participación en la búsqueda de alternativas de solución a los problemas y al progreso social y económico del país:

- la adquisición de una conciencia para la conservación, protección y mejoramiento del medio ambiente, de la calidad de la vida, del uso racional de los recursos naturales, de la prevención de desastres, dentro de una cultura ecológica y del riesgo y la defensa del patrimonio cultural de la Nación;

- la formación en la práctica del trabajo, mediante los conocimientos técnicos y habilidades, así como en la valoración del mismo como fundamento del desarrollo individual y social;

- la formación para la promoción y preservación de la salud y la higiene, la prevención integral de problemas socialmente relevantes, la educación física, la recreación, el deporte y la utilización adecuada del tiempo libre, y

- la promoción en la persona y la sociedad de la capacidad para crear, investigar, adoptar la tecnología que se requiere en los procesos de desarrollo del país y le permita al educando ingresar al sector productivo.

Aparato de organización de la asimilación. Se propone la organización del trabajo del material de estudio articulándolo, según corresponda, a los siguientes ejes: procesos de construcción de sistemas de significación; procesos de interpretación y producción de textos; procesos culturales y estéticos asociados al lenguaje: el papel de la literatura; principios de interacción y procesos culturales asociados a la ética de la comunicación; procesos de desarrollo del pensamiento. Igualmente, se orienta la dirección del trabajo por proyectos y la evaluación del aprendizaje por procesos indicando las categorías para el análisis de la comprensión lectora y para el análisis de textos escritos en contexto de evaluación. También, se señala la necesidad de trabajar el texto como unidad de análisis y, a partir de él, abordar elementos menores (oración, palabra, sílaba, grafía) para construir nuevos textos, del tratamiento de situaciones problémicas integradamente y con diversas ópticas; la proposición de actividades comunicativas y de actividades para descubrir los propósitos y fines de la escritura; la presentación de múltiples y atractivos acercamientos a los textos literarios.

Material ilustrativo. Uso de letra legible, distribución adecuada de espacios; presentación de ilustraciones nítidas y que gusten a los estudiantes, bien impresas, bien distribuidas. Material ilustrativo atractivo; motivador e impulsor.

Aparato de orientación. Presentación de los autores y de sus reseñas biobibliográficas; del año del copyright y del registro ISBN; de la tabla de contenido; información de los nombres del equipo evaluador y de los investigadores que hicieron las pruebas del texto; estructura clara; bibliografía consultada y recomendada.

Soporte material del contenido

Material de elaboración. Encuadernación resistente, papel de buena calidad, agradable al tacto; fácil de hojear; con carátula hermosa

Formato. Tamaño de fácil manejo por los estudiantes.

\section{CONCLUSIONES}

Con base en los planteamientos de Shishkova y Popok [6], es posible conceptuar que el libro de texto es un subgénero del género manual escolar del subestilo de divulgación científica del estilo funcional científico, y que su fin es servir de medio al proceso de enseñanza-aprendizaje. A partir de la reflexión sobre los libros de texto planteada por distintos autores, entre ellos fundamentalmente Zuev [5] y el MEN, en diversas publicaciones, se define el libro de texto de castellano para un grado de la EPC como aquel que 
comporta la presentación didáctica de los contenidos que el programa de estudios del área determina que deben ser asimilados por los estudiantes de ese grado; la presentación didáctica se manifiesta tanto en el contenido como en su soporte material. En Colombia, los contenidos son definidos por las normas estatales sobre la materia.

\section{REFERENCIAS BIBLIOGRÁFICAS}

[1] Álvarez De Zayas, C. M. La escuela en la vida. Didáctica. $3^{\circ}$ ed. Pueblo y Educación, Ciudad de La Habana, 1999

[2] Especialistas del Ministerio de Educación de Cuba. Pedagogía. Pueblo y Educación, Ciudad de La Habana, 1989

[3] BeLOZÉRTSEV, V. I. y otros. "El sistema de métodos de enseñanza en la educación superior". En La educación superior contemporánea. Revista internacional de países socialistas. № 4 / 64. MES, Ciudad de La Habana, 1988. Págs. 135-147

[4] Konstantinov, N. A. y otros. Historia de la pedagogía. Pueblo y Educación, Ciudad de La Habana, 1974

[5] Zuev, D. D. El libro de texto. Pueblo y Educación, Ciudad de La Habana, 1988

[6] SHISHKOVA, T. H. у POPOK, V. K. L. Estilística funcional. (s.e.), (s.c.),1989

[7] KLINGBERG, L. Introducción a la didáctica general. Pueblo y Educación, Gudad de La Habana, 1978

[8] Lerner, I. Ya. y SkAtKIN, M. N. "Métodos de enseñanza". En Danilov, M. A. y Skatkin, M. N. Didáctica de la escuela media. Editorial de libros para la educación, Ciudad de La Habana, 1980. Págs. 154-194

[9] NolÁn, B. y GoETS, D. Prontuario del escritor de materiales educativos. Pax-México, México, 1962

[10] HeRnández Ruiz, S. Metodología de la enseñanza. Tomo II, Uteha, México, 1969

[11] II REUNIÓN INTERAMERICANA DE EXPERTOS EN MATERIALES EDUCATIVOS Y BIBLIOTECAS EN ESPAÑOL. EI Mácaro, Turmero -Venezuela-, 1989

[12] TejadA, L. El libro de texto. Problemática de los materiales educativos impresos. Centro de Capacitación Docente 'El Mácaro', Venezuela, 1981

[13] TEJADA, L. y JAEN, A. Tendencias en la preparación de materiales educativos impresos. Problemática de los materiales educativos impresos. Centro de Capacitación Docente 'El Mácaro', Venezuela, 1989

[14] PeÑA, L. B. "El texto como facilitador del proceso de enseñanza-aprendizaje". En Revista El Educador. No. 8. Norma, Bogotá, 1987. Págs. 6-9

[15] "La importancia del libro de texto". En Revista El Educador. No. 7. Norma, Bogotá, 1986. Págs. $14-20$ 
[16] VANEGAS FonSECA, M. C. El texto escolar: cómo aprovecharlo. Ministerio de Educación Nacional de la República de Colombia - Centro Regional para el Fomento del Libro en América Latina y el Caribe, Bogotá, D. C., 1993

[17] Prendes Espinosa, M. P. "Evaluación de manuales escolares". En Píxel-BIT. Revista electrónica. www.sav.us.es/pixelbit/articulos/n9/n9art/art93.htm, 2003

[18] ChARRIA V., M. E. y otros. Orientaciones para la evaluación y selección de textos escolares. Ministerio de Educación Nacional, Santafé de Bogotá, 1995

[19] MolineR, M. Diccionario de uso del español. Tomo A-G. Gredos, Madrid, 1986

[20] RichaUdEAU, F. Concepción y producción de manuales escolares. Guía práctica. SECAB, CERLAC, Bogotá, 1981

[21] DeBuen UnNa, J. Manual de diseño editorial. Santillana, México, 2000

[22] MARTínez DeSOUSA, J. Diccionario de tipografía y del libro. 3º ed. Paraninfo, Madrid, 1992

[23] PeÑa BorRero, L. B. y Mejía Botero, W. Manual para la planeación, el diseño y la producción de libros de texto. Secretaría Ejecutiva del Convenio Andrés Bello, Santafé de Bogotá, 1995

[24] Ministerio De Educación NACIONAL. Ley General de Educación. Oficina de Comunicaciones. MEN, Santafé de Bogotá, 1994

[25] Ministerio de Educación Nacional. Procesos curriculares e indicadores de logros. Resolución 2343 del 5 de junio de 1996. Magisterio, Bogotá, D.C., 1996

[26] MinISTERIO De EdUCACIÓn NACIONAL. Estándares básicos de calidad en matemáticas y lenguaje. MEN, Bogotá, D.C. 2003

[27] Ministerio De EducAción NACIONAL. Lengua castellana. Lineamientos curriculares. Magisterio, Bogotá, D. C. 1998

[28] Ministerio De EdUCAción NAcional. Plan nacional de dotación de textos para la Educación Básica Primaria en Colombia. MEN, Bogotá, 1988 


\section{ANEXO 1}

Figura 1.

Modelo del libro de texto escolar de Zuev

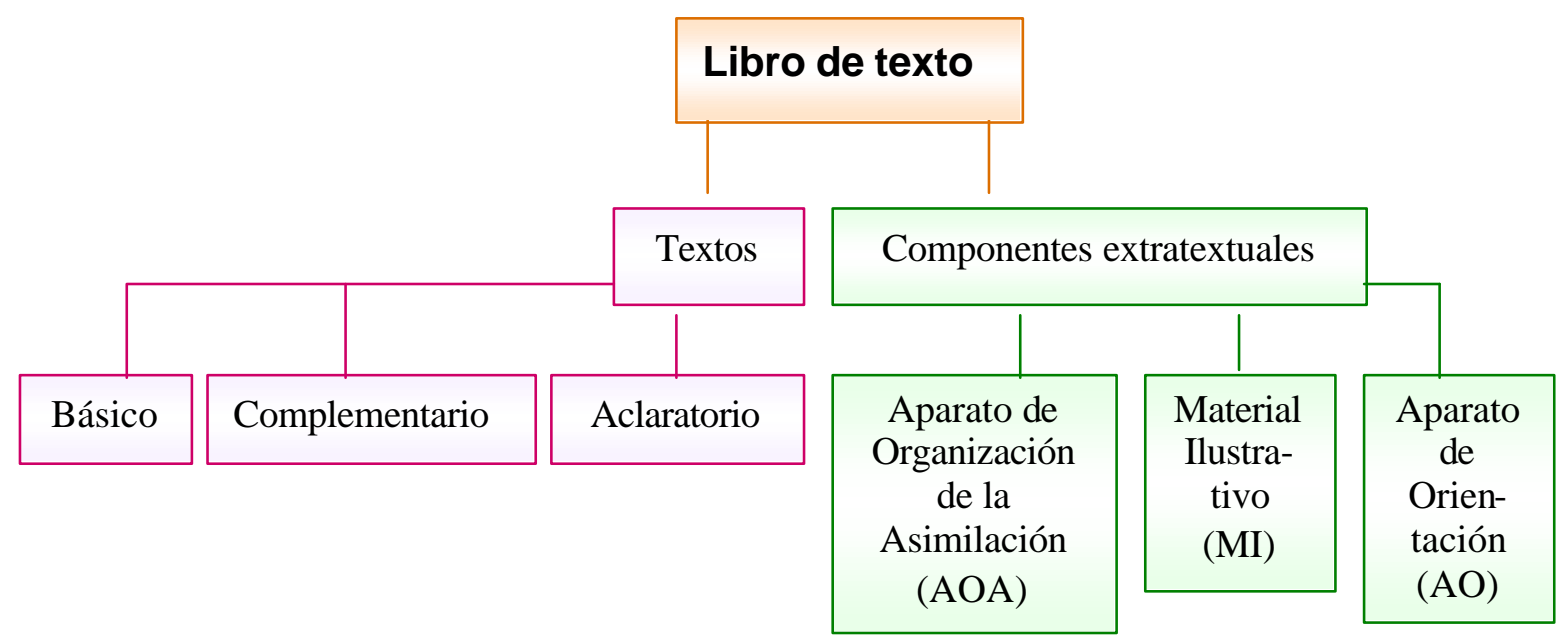




\section{ANEXO 2}

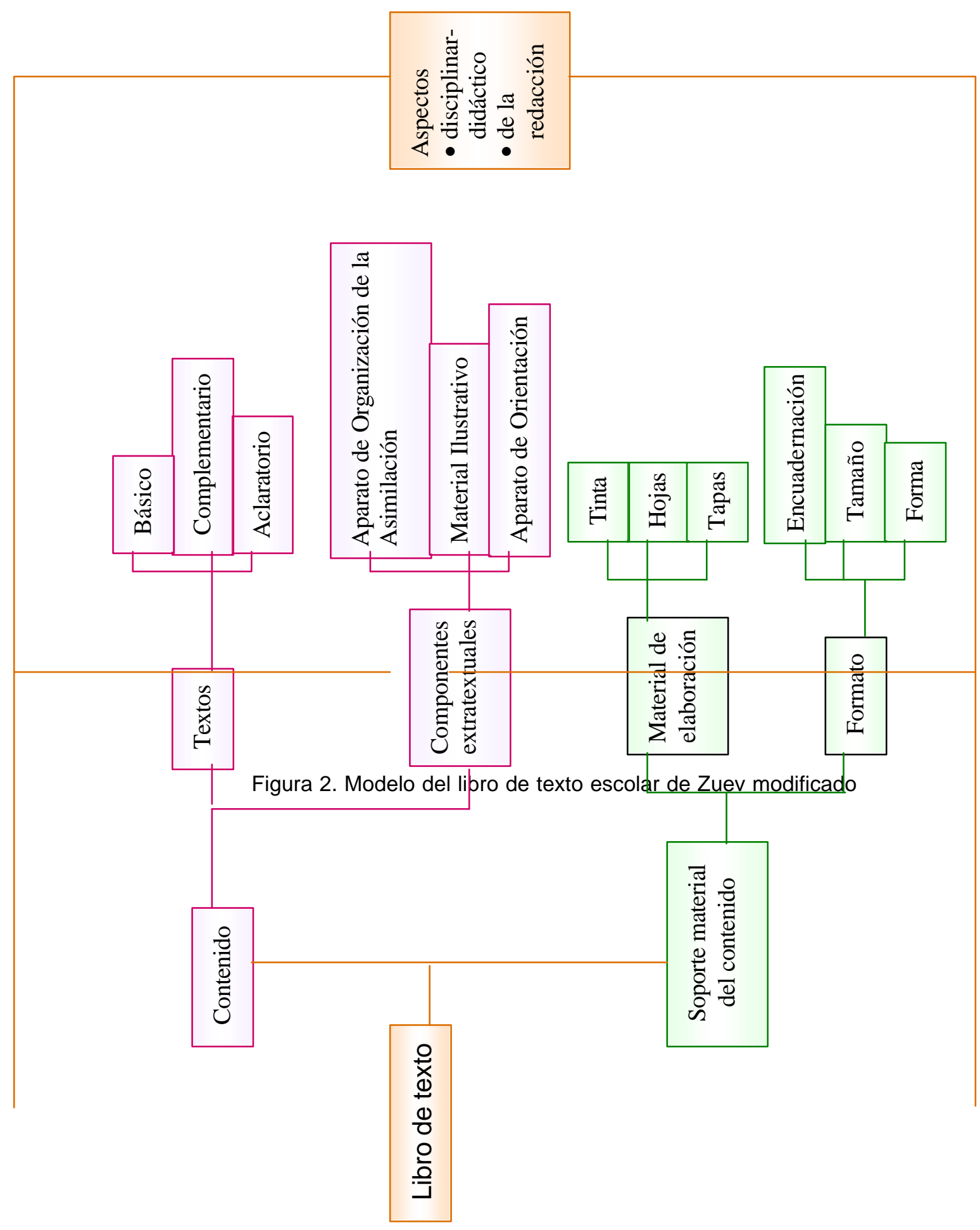




\title{
Contactar
}

Revista lberoamericana de Educación

\author{
Principal OEI
}

